University of New Hampshire

University of New Hampshire Scholars' Repository

Physics Scholarship

Physics

2-15-2003

\title{
Kinetic-energy release in Coulomb explosion of metastable C3H52+
}

K. Gluch

J. Fedor

S. Matt-Leubner

Olof E. Echt

University of New Hampshire, Olof.Echt@unh.edu

A. Stamatovic

See next page for additional authors

Follow this and additional works at: https://scholars.unh.edu/physics_facpub

Part of the Physics Commons

\section{Recommended Citation}

The following article appeared in J. Chem. Phys. 118, 3090 (2003); doi: 10.1063/1.1536978 and may be found at http://dx.doi.org/10.1063/1.1536978.

This Article is brought to you for free and open access by the Physics at University of New Hampshire Scholars' Repository. It has been accepted for inclusion in Physics Scholarship by an authorized administrator of University of New Hampshire Scholars' Repository. For more information, please contact Scholarly.Communication@unh.edu. 


\section{Authors}

K. Gluch, J. Fedor, S. Matt-Leubner, Olof E. Echt, A. Stamatovic, M. Probst, P. Scheier, and T. D. Mark 


\section{AIP Chemicical Prysics}

\section{Kinetic-energy release in Coulomb explosion of metastable C3H52+}

K. Głuch, J. Fedor, S. Matt-Leubner, O. Echt, A. Stamatovic et al.

Citation: J. Chem. Phys. 118, 3090 (2003); doi: 10.1063/1.1536978

View online: http://dx.doi.org/10.1063/1.1536978

View Table of Contents: http://jcp.aip.org/resource/1/JCPSA6/v118/i7

Published by the American Institute of Physics.

Additional information on J. Chem. Phys.

Journal Homepage: http://jcp.aip.org/

Journal Information: http://jcp.aip.org/about/about_the_journal

Top downloads: http://jcp.aip.org/features/most_downloaded

Information for Authors: http://jcp.aip.org/authors

\section{ADVERTISEMENT}
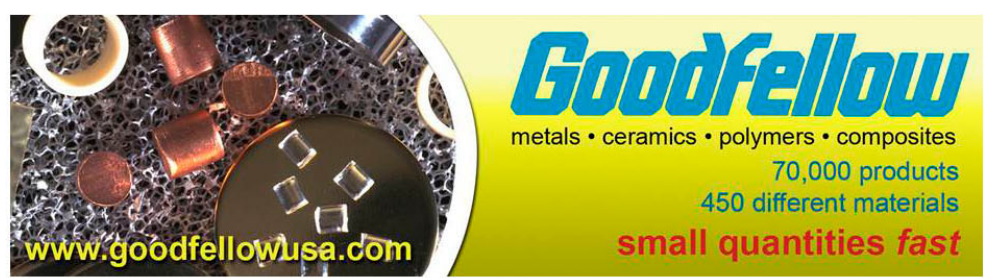


\title{
Kinetic-energy release in Coulomb explosion of metastable $\mathrm{C}_{3} \mathrm{H}_{5}^{2+}$
}

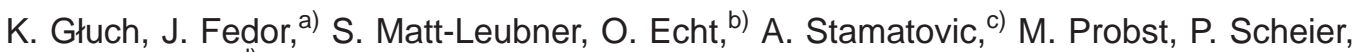 \\ and T. D. Märk ${ }^{d)}$ \\ Institut für Ionenphysik, Leopold Franzens Universität, Technikerstr. 25, A-6020 Innsbruck, Austria
}

(Received 17 July 2002; accepted 20 November 2002)

$\mathrm{C}_{3} \mathrm{H}_{5}^{2+}$, formed by electron impact ionization of propane, undergoes metastable decay into $\mathrm{C}_{2} \mathrm{H}_{2}^{+}+\mathrm{CH}_{3}^{+}$. We have monitored this reaction in a magnetic mass spectrometer of reversed geometry that is equipped with two electric sectors (BEE geometry). Three different techniques were applied to identify the fragment ions and determine the kinetic-energy release (KER) of spontaneous Coulomb explosion of $\mathrm{C}_{3} \mathrm{H}_{5}^{2+}$ in the second and third field free regions of the mass spectrometer. The KER distribution is very narrow, with a width of about 3\% [root-mean square standard deviation]. An average KER of $4.58 \pm 0.15 \mathrm{eV}$ is derived from the distribution. High level $a b$ initio quantum-chemical calculations of the structure and energetics of $\mathrm{C}_{3} \mathrm{H}_{5}^{2+}$ are reported. The activation barrier of the reverse reaction, $\mathrm{CH}_{3}^{+}+\mathrm{C}_{2} \mathrm{H}_{2}^{+}$(vinylidene), is computed. The value closely agrees with the experimental average KER, thus indicating that essentially all energy available in the reaction is partitioned into kinetic energy. (c) 2003 American Institute of Physics.

[DOI: $10.1063 / 1.1536978]$

\section{INTRODUCTION}

A large number of small, doubly charged molecules have been observed in the gas phase (for recent reviews, see Refs. 1 and 2). Some of them, even diatomic systems, are thermochemically stable, i.e., charge separation is an endothermic reaction. ${ }^{3}$ The majority of them, however, are metastable, and charge separation, which may occur by tunneling, thermal activation, curve crossing or other mechanisms, results in two ionic fragments that are accelerated to several $\mathrm{eV}$ in their mutual electrostatic field (Coulomb explosion). It has been suggested that these systems may be used for energy storage. $^{4}$

There has been a renewed interest in the dynamics and decay mechanism of doubly charged species, partly stimulated by the development of new experimental techniques. For example, photoelectron-ion-ion triple coincidence spectra make it possible to map the change in charge distribution during Coulomb explosion. ${ }^{5}$ Using this technique, Eland and co-worker ${ }^{6}$ demonstrated that $\mathrm{C}_{3} \mathrm{H}_{4}^{2+}$, produced by onephoton ionization of propane, undergoes delayed charge separation into $\mathrm{H}^{+}+\mathrm{C}_{3} \mathrm{H}_{3}^{+}$on the time scale of $<100 \mathrm{~ns}$, while Lundqvist et al. $^{7}$ were able to resolve vibrational structure in kinetic-energy release distributions. Another approach, based on the combination of coincidence techniques with position-sensitive detectors, provides images of the molecular break-up. ${ }^{8}$

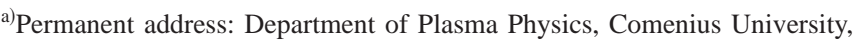
Mlynska dolina F2, SK-84215 Bratislava, Slovak Republic.

${ }^{b)}$ Permanent address: Department of Physics, University of New Hampshire, Durham, New Hampshire 03824, USA.

${ }^{c}$ Permanent address: Faculty of Physics, P.O. Box 638, Yu-11001 Beograd, Yugoslavia.

d) Author to whom correspondence should be addressed. Also adjunct professor, Department of Plasma Physics, Comenius University, Mlynska dolina F2, SK-84215 Bratislava, Slovak Republic. Electronic mail: tilmann.maerk@uibk.ac.at
}

Another accurate procedure to measure kinetic-energy release distributions is the MIKE (mass-analyzed ion kinetic energy) scan technique. It has been applied to several systems that are unstable with respect to Coulomb explosion, prepared by charge stripping, photon or electron impact ionization of singly charged precursors. ${ }^{1,9}$ Other reports pertain to metastable decay of doubly charged molecules ${ }^{10-13}$ and clusters. ${ }^{14}$

In the present work we analyze spontaneous (metastable) Coulomb explosion of $\mathrm{C}_{3} \mathrm{H}_{5}^{2+}$ which is formed by electron impact ionization of propane. Ab initio quantum-chemical calculations to be presented in this work suggest that this dication is vibrationally predissociated. We employ a double focusing magnetic mass spectrometer of reversed geometry that is equipped with a second electric field sector (BEE geometry). This allows us to identify fragment ions, and their kinetic energy, produced by Coulomb explosion,

$$
\mathrm{C}_{3} \mathrm{H}_{5}^{2+} \rightarrow \mathrm{C}_{2} \mathrm{H}_{2}^{+}+\mathrm{CH}_{3}^{+} \text {. }
$$

Identification of the $\mathrm{CH}_{3}^{+}$fragment ion in a conventional MIKE scan is difficult due to contamination that arises from other decay reactions in the first field-free region of the mass spectrometer. However, MIKE scans that employ the second electric sector field avoid this problem. This approach allows us to unambiguously identify both product ions in the metastable decay of $\mathrm{C}_{3} \mathrm{H}_{5}^{2+}$. Reaction channels that compete with (1) have been observed as well; they will be subject of a future publication. An accurate value is determined for the average kinetic-energy release of reaction (1), 4.58 $\pm 0.15 \mathrm{eV}$. The width of the KER distribution (rms standard deviation) is estimated to be no more than $3 \%$.

$A b$ initio calculations were performed at the MP2/6-31G**15 level to determine the potential energy of $\mathrm{C}_{3} \mathrm{H}_{5}^{2+}$ as a function of the $\mathrm{H}_{2} \mathrm{CC}^{+}-\mathrm{CH}_{3}^{+}$distance with all other coordinates optimized. A more accurate value for the 


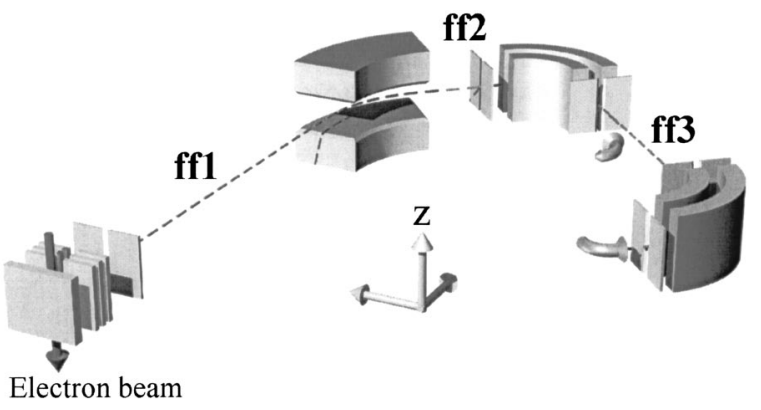

FIG. 1. Schematic drawing of the experimental setup.

energy difference between the transition state configuration and the ground states of the product ions (with $\mathrm{C}_{2} \mathrm{H}_{2}^{+}$being in the vinylidene geometry) was then determined from $\operatorname{CCSD}(\mathrm{T}) / \mathrm{cc}-\mathrm{pVTZ//MP2/aug-cc-pVTZ} \mathrm{calculations.} \mathrm{The} \mathrm{re-}$ sult, $4.37 \mathrm{eV}$, is in close agreement with the experimental KER.

\section{EXPERIMENT}

Details of the experimental setup and data analysis have been published elsewhere. ${ }^{16,17}$ As shown in Fig. 1, the apparatus consists of a high-resolution double focusing mass spectrometer (Varian MAT CH5-DF) of reversed NierJohnson type BE1 geometry combined with a second electrostatic analyzer E2. Propane (purity 99.95\%, AGA Gas $\mathrm{GmbH})$ is introduced via a capillary leak gas inlet system into the collision chamber of a Nier type ion source where it is ionized by an electron beam of variable energy and current. Ensuing cations are extracted by a weak electric field and accelerated through a potential drop of $U_{\mathrm{ac}}=3 \mathrm{kV}$ into the spectrometer. They pass through the first field free region (ff1, length $61 \mathrm{~cm}$ ), are momentum-analyzed by a magnetic sector field B, enter a second field-free region (ff2, length $33.3 \mathrm{~cm}$ ), pass through a $90^{\circ}$ electric sector field (E1), enter a third field free region (ff3, length $92 \mathrm{~cm}$ ), pass through another electrostatic sector field (E2, geometry identical with E1), and finally are detected by a channeltron-type electron multiplier. Alternatively, another channeltron-type electron multiplier may be moved into the ion beam to register all ions that pass through the exit slit of $\mathrm{E} 1 . \mathrm{C}_{3} \mathrm{H}_{5}^{2+}$ parent ions traverse ff 2 during the time interval $7.6 \leqslant t \leqslant 9.7 \mu \mathrm{s}$, and ff 3 during $11.3 \leqslant t \leqslant 16.9 \mu \mathrm{s}$.

Mass-analyzed ion kinetic energy (MIKE) spectra of parent ions $m_{p}^{z_{p}+}$ (i.e., ions of mass $m_{p}$, charge state $z_{p}$ ) that undergo spontaneous decay in $\mathrm{ff} 2$

$$
m_{p}^{z_{p}{ }^{+}} \rightarrow m_{f}^{z_{f}^{+}}+\text {neutral and/or charged particles, }
$$

are monitored as follows: ${ }^{18}$ The magnet is tuned to transmit the parent ion, while the sector field voltage $U$ of E1 is scanned. If $U_{p}$ denotes the voltage required to transmit a stable parent ion ( $U_{p} \approx 510.9 \mathrm{~V}$ in our system), then the electric sector will transmit fragment ions $m_{f}^{z_{f}^{+}}$formed in ff2 if the sector field voltage is set to

$$
U_{f}=\frac{m_{f} z_{p}}{m_{p} z_{f}} U_{p} .
$$

Likewise, decay of $m_{p}^{z_{p}+}$ in ff3 is analyzed by tuning the magnet to transmit the parent ion, setting the voltage of E1 to $U_{p} \approx 510.9 \mathrm{~V}$ such that it transmits stable parent ions, and scanning the sector field voltage of E2. As before, Eq. (3) applies. In this mode, B and E1 constitute a double focusing high-resolution mass spectrometer.

In a third mode, ${ }^{19}$ identical voltages $U$ are applied to E1 and E2; this voltage is then scanned. Ions $m_{f}^{z_{f}^{+}}$produced in ff2 will be transmitted through E1 and E2 if $U$ satisfies Eq. (3).

So far we have ignored the fact that the parent ions have a finite kinetic-energy distribution that will give rise to a finite width and characteristic peak shape in the MIKE scans. Furthermore, any kinetic-energy release (KER) in reaction (1) will modify the peak shape of the fragment ion. Three commonly encountered peak shapes are as follows: ${ }^{16,18,20}$

(a) A Gaussian peak occurs if the kinetic-energy release follows a Maxwell-Boltzmann distribution (often encountered if the reaction features no reverse activation barrier), and the exit slit of the electric sector field is long enough such that it does not discriminate against ions that are emitted in $z$ direction, i.e., perpendicular to the beam axis and parallel to the length of the slit (see Fig. 1).

(b) A nearly rectangular peak is observed if the kineticenergy release is single-valued and small such that the exit slit of the electric sector field does not discriminate against ions that are emitted in $z$ direction.

(c) A dished peak occurs if the kinetic-energy release is single-valued and large such that the finite length of the exit slit gives rise to strong discrimination against ions that are emitted with large $z$ components. In the case of extreme discrimination, one will observe a double peak (called a split peak throughout the remainder of this work) that is located symmetrically with respect to the sector field voltage defined by Eq. (3). The high-energy component of the split peak arises from ions that dissociate with the fragment of interest being expelled in the forward direction; it will be somewhat more intense than the low-energy component due to different degrees of discrimination.

In the present work we encounter strongly dished peaks. In this situation, one usually estimates the average kineticenergy release, $\bar{\varepsilon}$, from the separation of the two "horns" of the split peak, $\Delta U$, with help of the relation. ${ }^{11,20}$

$$
\bar{\varepsilon}=\frac{z_{f}^{2} m_{p}^{2} U_{a c}}{16 z_{p} m_{f}\left(m_{p}-m_{f}\right)}\left(\frac{\Delta U}{U_{p}}\right)^{2} .
$$

Here it is assumed that the reaction produces only two products; an assumption that is met in the present situation, i.e., decay of $\mathrm{C}_{3} \mathrm{H}_{5}^{2+}$.

However, this procedure tends to underestimate the average KER. ${ }^{12}$ In the present work, we apply a more accurate procedure: We first derive the KER distribution from the MIKE spectra as described in the following paragraph; the average KER is then computed from this distribution by numerical integration. 
Extreme dishing indicates strong geometric discrimination due to the finite lengths of the analyzing slits. In this situation, fragment ions are observed only if they are ejected very nearly parallel or antiparallel to the trajectory of the parent ion beam (in the lab reference frame). The outer wings of a split peak (i.e., either section outside of the "horns;" metastable peaks are essentially symmetric with respect to their centroid) will, therefore, reflect the speed distribution of fragment ions. On the other hand, the steepness of the inner wing merely reflects the degree of geometrical discrimination. The KERD is obtained from the outer wing by taking the derivative $d I / d(\delta U)$, where $I(\delta U)$ is the measured ion intensity, and $\delta U$ is the sector field voltage referenced to the centroid of the split peak. Finally, $\delta U$ has to be transformed to KER values with help of Eq. (4), using $\Delta U$ $=2 \delta U^{16,21}$

This procedure would be exact in the absence of other broadening mechanisms, like spread of kinetic energy of parent ions, finite slit widths, finite diameter and divergence of the parent ion beam. We have previously studied, by numerical simulation of ion trajectories, the effect that these factors have on the shape of MIKE peaks in a magnetic mass spectrometer of reversed (BE) geometry, see Fig. 3 in Ref. 16. Such a detailed simulation is not possible in the present case (BEE geometry), but our experimental results presented below indicate that the broadening due to geometric factors is greatly reduced for measurements that exploit both electric sector fields. Furthermore, the parent ion peak is also broadened by these mechanisms. Hence, their effect on the metastable peak shape is eliminated, at least to first order, by proper deconvolution with the parent ion peak.

In summary, the following procedure is applied to derive the KER distribution, and from it the average KER: A pair of asymmetric Gaussians with identical amplitude, width $w$ (rms standard deviation) and asymmetry parameters are fitted to the split peak in question. This fit function is then deconvoluted with a Gaussian that was fitted to the parent ion peak and scaled to the sector field voltage corresponding to the centroid of the split peak. The derivative of the deconvoluted function will then, after conversion from sector field voltage to KER, provide the KER distribution. The procedure will not be able to reveal fine details of the KER distribution because it relies on a fit function that involves only a small number of parameters, but the average KER computed from this distribution should be accurate.

\section{RESULTS AND DISCUSSION}

Figure 2(a) presents the MIKE spectrum obtained for Coulomb explosion of $\mathrm{C}_{3} \mathrm{H}_{5}^{2+}$ in ff2. According to Eq. (3), the fragment ion $\mathrm{CH}_{3}^{+}$will produce a metastable peak at a sector field voltage $U=374$ or, if the KER is large, a pair of peaks placed symmetrically with respect to $U=374 \mathrm{~V}$. Instead, we observe several peaks when $U$ is scanned from 320 to $410 \mathrm{~V}$. Most of these peaks are artifacts; they arise from decay of metastable ions $m_{1}^{z_{1}+}$ into $m_{2}^{z_{2}+}$ (with $m_{2}<m_{1}$, $z_{2} \leqslant z_{1}$ ) in ff1, before the magnet. These fragment ions $m_{2}^{z_{2}+}$ will be transmitted through the magnet, and contribute to the MIKE spectrum, if their apparent mass $m^{*}=m_{2}^{2} z_{1} /\left(z_{2}^{2} m_{1}\right)$ is

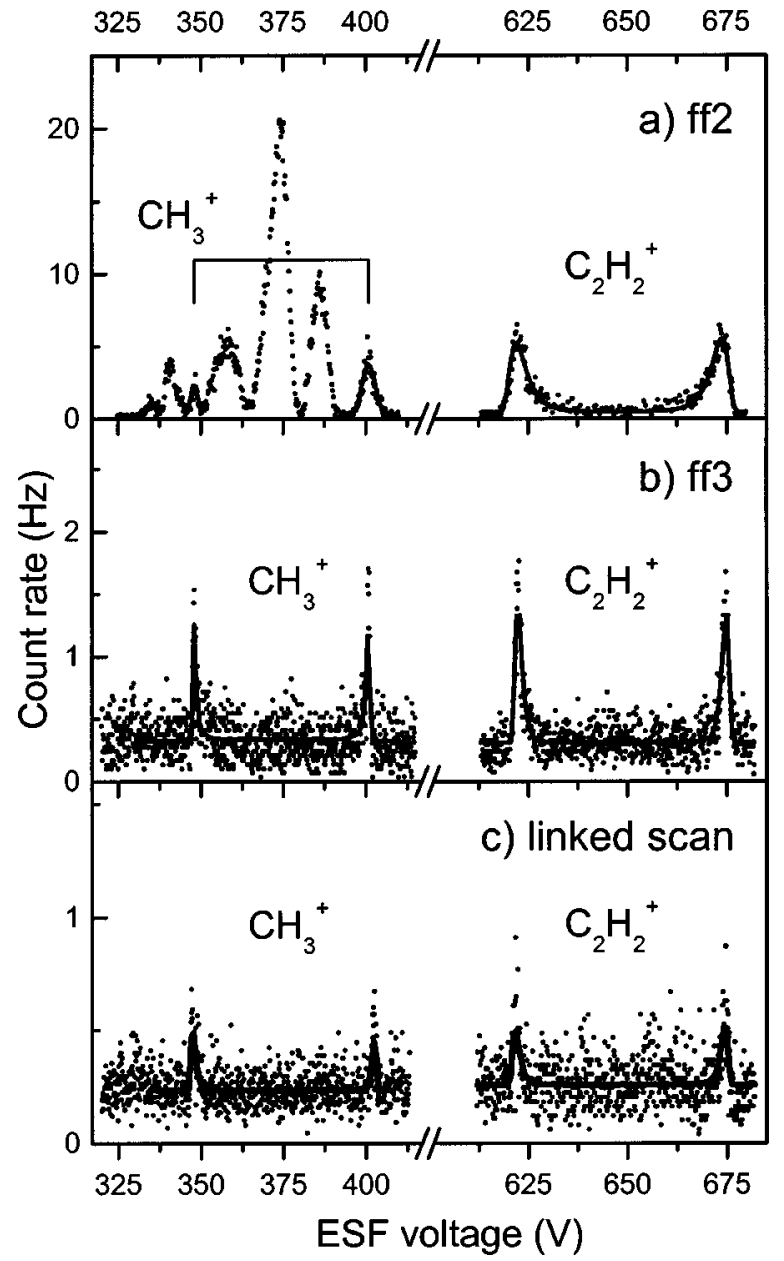

FIG. 2. Three scans of electric sector field voltages that reveal the formation of fragment ions, $\mathrm{CH}_{3}^{+}$and $\mathrm{C}_{2} \mathrm{H}_{2}^{+}$, from $\mathrm{C}_{3} \mathrm{H}_{5}^{2+}$ : (a) MIKE scan of E1, monitoring metastable reactions in ff2. (b) MIKE scan of E2, monitoring metastable reactions in ff3. (c) Synchronous scan of E1 and E2, monitoring reactions in $\mathrm{ff} 2$. Each split peak corresponds to one specific fragment ion that recoils either parallel or antiparallel to the ion beam axis. Solid lines indicate nonlinear least-squares fits of pairs of asymmetric Gaussians.

approximately equal to $m_{p} / z_{p}=41 / 2$. These artifact peaks are a common nuisance in "normal" MIKE spectra if decay of polyatomic molecules or large atomic clusters is analyzed. ${ }^{18,22}$ Hence, the left half of Fig. 2(a) does not provide unambiguous information about the decay channels of $\mathrm{C}_{3} \mathrm{H}_{5}^{2+}$.

However, reaction (1) produces another charged fragment, $\mathrm{C}_{2} \mathrm{H}_{2}^{2+}$. According to Eq. (3), this ion shows up in a MIKE scan at $U=648 \mathrm{~V}$. Figure 2(a) reveals, indeed, a widely separated pair of peaks that are located symmetrically with respect to $648 \mathrm{~V}$. As described in Sec. II, this peak shape indicates that the KER is single valued and large, such that only fragment ions that dissociate in either forward or backward direction contribute to the detector signal. We also note that this part of the MIKE scan is free of contamination by artifact peaks because fragment ions produced in ff1 cannot appear above $U=U_{p}$ unless formed by charge separation.

In Fig. 2(b) we display sections of MIKE spectra recorded in ff3. This spectrum is free of artifact peaks, even for $U<U_{p}$, because ions that are formed in ff1 have a reduced kinetic energy and will not be transmitted through E1 into 


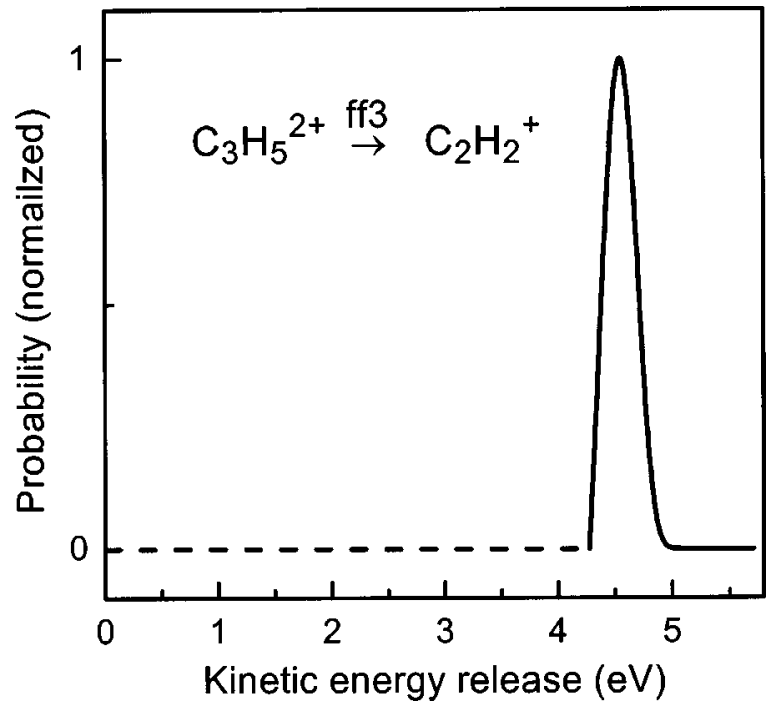

FIG. 3. Kinetic-energy release distribution for decay of $\mathrm{C}_{3} \mathrm{H}_{5}^{2+}$ in $\mathrm{ff3}$. The distribution is derived from the fit to the outer wing of the $\mathrm{C}_{2} \mathrm{H}_{2}^{+}$daughter ion peak shown in Fig. 2(b).

ff3. ${ }^{19}$ This spectrum provides unambiguous evidence for the occurrence of $\mathrm{CH}_{3}^{+}$and $\mathrm{C}_{2} \mathrm{H}_{2}^{+}$. The assigned masses (15.02 and $26.02 \mathrm{u}$ ) agree with those derived from the centroids of the split peaks with help of Eq. (3) within $\pm 0.03 \mathrm{u}$. Hence, this is a two-body reaction; no neutrals are produced in this channel.

MIKE spectra recorded by a linked scan of E1 and E2 are displayed in Fig. 2(c). By and large, this spectrum is similar to the ff3 MIKE scan, but the count rate is reduced further to a point where detector noise dominates the spectrum. Data were acquired for about 24 hours. Note that the peaks in this scan, as well as in the ff3 MIKE scan [Fig. 2(b)], are significantly narrower than in the ff2 MIKE scan, Fig. 2(a). This is a result of enhanced discrimination against fragment ions that do not recoil exactly in forward or backward direction. ff 3 is nearly three times longer than ff2, hence the average distance between the point of fragmentation and the beam-defining exit slit is larger, and the acceptance angle is smaller. By this argument, the linked scan should produce the narrowest peaks, but the statistical noise in this spectrum precludes a reliable estimate of the peak width.

We now turn to an analysis of the kinetic energy released in Coulomb explosion of $\mathrm{C}_{3} \mathrm{H}_{5}^{2+}$. The average KER may be estimated from the separation of the two "horns" of a split peak with help of Eq. (4). ${ }^{11,20}$ In the present work, this results in a KER of $4.36 \pm 0.19 \mathrm{eV}$. This value is obtained as a weighted average of five different values, namely all split peaks shown in Fig. 2 except for the less reliable $\mathrm{CH}_{3}^{+}$MIKE peak measured in ff2. The quoted uncertainty reflects the rms standard deviation of those five values.

However, as discussed in the experimental section, the procedure described in the preceding paragraph tends to produce KER values that are too low. ${ }^{12}$ A more accurate, unbiased value can be obtained from the KER distribution which, in turn, is computed from the function that is fitted to each split peak. Figure 3 shows, as an example, the KER distribu- a)

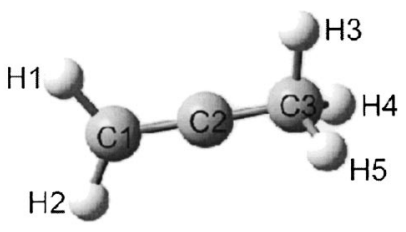

b)
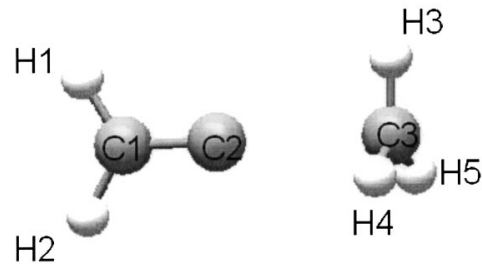

c)

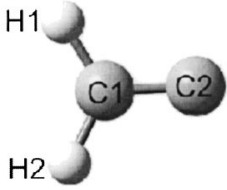

d)

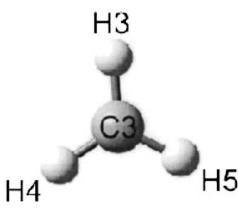

FIG. 4. Structure of $\mathrm{C}_{3} \mathrm{H}_{5}^{2+}$ in (a) the ground state, (b) the transition state, (c) $\mathrm{C}_{2} \mathrm{H}_{2}^{+}$(vinylidene), and (d) $\mathrm{CH}_{3}^{+}$. All structures obtained at the MP2/ aug-cc-pVTZ level. Coordinates are fully optimized, except for the $\mathrm{C} 2-\mathrm{C} 3$ separation in the transition state.

tion that is derived, after deconvolution with the parent ion peak, from the $\mathrm{C}_{2} \mathrm{H}_{2}^{+}$MIKE peak measured in ff3. The distribution peaks sharply at $4.5 \mathrm{eV}$; its width measures only $3 \%$ (rms std dev), or 6\% full width at half maximum (FWHM).

We have similarly derived the KER distributions for the other MIKE peaks displayed in Fig. 2. From each of those distributions we compute average KER values by numerical integration; their uncertainties are estimated from the uncertainties of the fit parameters (splitting $\Delta U$ and steepness of the wings, $w$ ). Combining all values, but again excluding the $\mathrm{CH}_{3}^{+}$MIKE peak measured in ff2, we obtain the weighted average, $\langle$ KER $\rangle=4.58 \pm 0.15 \mathrm{eV}$.

\section{QUANTUM-CHEMICAL CALCULATIONS}

In order to examine the fragmentation process involved in the decay, we performed ab initio quantum-chemical calculations. In principle there are various possible reasons for the metastable decay of ions, for example vibrational predissociation of the parent ion in its ground electronic state, rotational predissociation, production of the parent ion in a metastable, electronically excited state, etc. We examined the first possibility by calculating the ground-state potentialenergy surface of $\mathrm{C}_{3} \mathrm{H}_{5}^{2+}$.

All calculations were performed using the GAUSSIAN 98 program package ${ }^{23}$ on a SGI Origin 3800 computer and a Linux workstation. Figure 4 shows the lowest energy MP2/aug-cc-pVTZ ${ }^{24}$ structure of Fig. 4(a) $\mathrm{C}_{3} \mathrm{H}_{5}^{2+}$ (doublet, $C_{s}$ symmetry), Fig. $4(\mathrm{~b}) \mathrm{C}_{3} \mathrm{H}_{5}^{2+}$ in the transition state, Fig. $4\left(\right.$ c) $\mathrm{C}_{2} \mathrm{H}_{2}^{+}$(doublet, $C_{2 v}$ symmetry), and Fig. $4\left(\right.$ d) $\mathrm{CH}_{3}^{+}$(sin- 
TABLE I. Computed bond lengths $R$ and angles $A$ in $\mathrm{C}_{3} \mathrm{H}_{5}^{2+}, \mathrm{C}_{2} \mathrm{H}_{2}^{+}$(vinylidene, in ${ }^{2} A_{1}$ ), and $\mathrm{CH}_{3}^{+}$in their ground states, and in the $\mathrm{C}_{3} \mathrm{H}_{5}^{2+}$ transition state. All values in angstroms and degrees, respectively.

\begin{tabular}{|c|c|c|c|c|c|c|}
\hline \multicolumn{3}{|c|}{$\mathrm{C}_{3} \mathrm{H}_{5}^{2+}$} & \multicolumn{2}{|l|}{$\mathrm{C}_{2} \mathrm{H}_{2}^{+}$} & \multicolumn{2}{|l|}{$\mathrm{CH}_{3}^{+}$} \\
\hline Coordinate & $\begin{array}{l}\text { Ground-state } \\
\text { value }\end{array}$ & $\begin{array}{c}\text { Transition state } \\
\text { value }\end{array}$ & Coordinate & Value & Coordinate & Value \\
\hline$R(\mathrm{C} 1-\mathrm{C} 2)$ & 1.356 & 1.367 & $R(\mathrm{C} 1-\mathrm{C} 2)$ & 1.246 & $R(\mathrm{C} 3-\mathrm{H} 3)$ & 1.068 \\
\hline$R(\mathrm{C} 2-\mathrm{C} 3)$ & 1.334 & 2.55 & $R(\mathrm{C} 1-\mathrm{H} 1)$ & 1.10 & $A(\mathrm{H} 3-\mathrm{C} 3-\mathrm{H} 5)$ & 120.0 \\
\hline$R(\mathrm{C} 1-\mathrm{H} 1)$ & 1.107 & 1.108 & $A(\mathrm{C} 2-\mathrm{C} 1-\mathrm{H} 1)$ & 118.4 & & \\
\hline$R(\mathrm{C} 3-\mathrm{H} 3)$ & 1.146 & 1.087 & & & & \\
\hline$R(\mathrm{C} 3-\mathrm{H} 4)$ & 1.264 & 1.087 & & & & \\
\hline$A(\mathrm{C} 1-\mathrm{C} 2-\mathrm{C} 3)$ & 180.0 & 180.0 & & & & \\
\hline$A(\mathrm{C} 2-\mathrm{C} 1-\mathrm{H} 1)$ & 120.46 & 120.25 & & & & \\
\hline$A(\mathrm{C} 2-\mathrm{C} 3-\mathrm{H} 3)$ & 103.24 & 92.03 & & & & \\
\hline$A(\mathrm{C} 2-\mathrm{C} 3-\mathrm{H} 5)$ & 113.32 & 91.99 & & & & \\
\hline$A(\mathrm{H} 3-\mathrm{C} 3-\mathrm{H} 5)$ & 106.96 & 119.82 & & & & \\
\hline
\end{tabular}

glet, $D_{3 h}$ symmetry). All coordinates are relaxed except for the $\mathrm{C} 2-\mathrm{C} 3$ separation in the transition state. Bond lengths and bond angles are listed in Table I.

Note that the $\mathrm{C}_{2} \mathrm{H}_{2}^{+}$ion ( $C_{2 v}$, vinylidene) is a structural isomer of the acetylene ion which is some $2 \mathrm{eV}$ lower in energy. ${ }^{25-27}$ Recent charge inversion mass spectra of $\mathrm{C}_{2} \mathrm{H}_{2}^{+}$, produced by electron ionization from $\mathrm{H}_{2} \mathrm{C}-\mathrm{CCl}_{2}$ provide, indeed, compelling evidence for the existence of a long-lived vinylidene cation. ${ }^{28}$ According to Baker ${ }^{25}$ and Jursic, ${ }^{27}$ the electronic ground state of vinylidene has ${ }^{2} A_{1}$ symmetry while Hamilton and $\operatorname{Schaefer}^{26}$ place ${ }^{2} B_{1}$ below ${ }^{2} A_{1}$. At any rate, the energy difference between these two states is very small, about $0.1 \mathrm{eV}$ or less. Our calculations were performed on ${ }^{2} A_{1}$; computed bond lengths and angles (Table I) agree very well with those reported by others. ${ }^{25,27}$

The ${ }^{2} A_{1}$ state features an extremely shallow barrier towards isomerization; ${ }^{25,27}$ product ions formed in ${ }^{2} A_{1}$ would isomerize to acetylene within the time interval required for ion detection. However, this isomerization would not significantly affect the experimental KER value because it does not involve charge separation. Similarly, even if Coulomb explosion of $\mathrm{C}_{3} \mathrm{H}_{5}^{2+}$ would yield vinylidene product ions in ${ }^{2} B_{1}$ (which features a barrier of about $0.5 \mathrm{eV}$ towards isomerization ${ }^{25,26}$ ), one would still expect the same KER because ${ }^{2} B_{1}$ and ${ }^{2} A_{1}$ are virtually iso-energetic.

The structures shown in Fig. 4 suggest that the fragmentation occurs by breaking of the $\mathrm{C} 2-\mathrm{C} 3$ bond. Figure 5 shows the potential energy of $\mathrm{C}_{3} \mathrm{H}_{5}^{2+}$ as a function of the C2-C3 distance, with all other coordinates optimized, obtained at the MP2/6-31G**15 level. For a more accurate determination of the energetics, final $\operatorname{CCSD}(\mathrm{T}) / \mathrm{cc}-\mathrm{pVTZ//}$ MP2/aug-cc-pVTZ calculations (single point energy $\operatorname{CCSD}(\mathrm{T}) / \mathrm{cc}-\mathrm{pVTZ}$ calculation performed on the structure optimized at the MP2/aug-cc-pVTZ level) for the transition state and the ground states of the products were carried out. They result in a reverse barrier of $4.37 \mathrm{eV}$. This value closely agrees with the experimentally determined average kinetic energy, $\langle\mathrm{KER}\rangle=4.58 \pm 0.15 \mathrm{eV}$. The agreement implies that essentially all the available energy is partitioned into kinetic energy. The origin of this unusual result becomes apparent from an inspection of the structures in Fig. 4, and the coordinates in Table I: In the transition state, the $\mathrm{CH}_{3}^{+}$and $\mathrm{C}_{2} \mathrm{H}_{2}^{+}$ groups have already adopted geometries that closely resemble their geometries in the product state. Hence, very little energy will be partitioned into internal degrees of freedom when the groups separate past the transition state, and the distribution of kinetic energies will necessarily be very narrow.

In the absence of $a b$ initio calculations, one often estimates the fragment separation in the transition state by equating the experimentally determined $\langle\mathrm{KER}\rangle$ with the potential energy of two point charges separated by $r_{\mathrm{TS}}$ in vacuum, and assuming that $r_{\mathrm{TS}}$ corresponds to the length of the bond that will break. ${ }^{11-13,18}$ In this model, $\bar{\varepsilon}=4.58$ $\pm 0.15 \mathrm{eV}$ would correspond to $r_{\mathrm{TS}}=3.14 \pm 0.10 \AA$ which is much longer than the $\mathrm{C} 2-\mathrm{C} 3$ bond $(2.55 \AA$, see Table I), but much less than the $\mathrm{C} 1-\mathrm{C} 3$ separation $(3.92 \AA)$. The flaw in this kind of analysis is in the incorrect assumption about the charge distribution in the transition state. A Mulliken charge analysis reveals that the net charge on $\mathrm{C} 1$ is only 0.002 , but it is +0.418 on $\mathrm{C} 2$, and another +0.298 on each of the two terminal hydrogen atoms of the vinylidene group. Similarly,

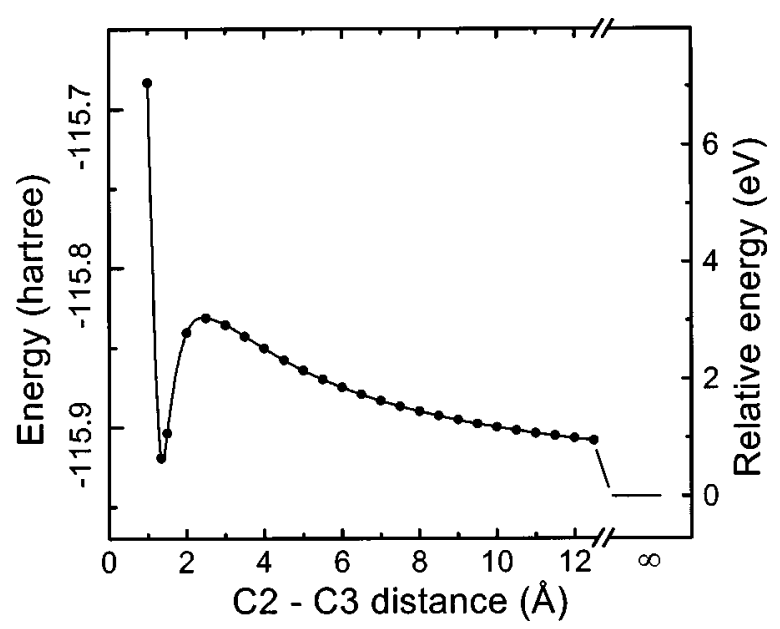

FIG. 5. Potential energy of $\mathrm{C}_{3} \mathrm{H}_{5}^{2+}$ as a function of the $\mathrm{H}_{2} \mathrm{CC}^{+}-\mathrm{CH}_{3}^{+}$distance (C2-C3 in Fig. 4) with all other coordinates optimized, obtained at the MP2/6-31G** level. The energy of the fully separated fragments, with $\mathrm{C}_{2} \mathrm{H}_{2}^{+}$in $C_{2 v}$, is indicated to the far right. At a higher level of the theory (see text), the reverse activation barrier is computed to be $4.37 \mathrm{eV}$. 
it is only +0.224 on $\mathrm{C} 3$ while the remaining charge resides on the hydrogen atoms of the methyl group. Thus, in the absence of detailed information about the charge distribution in the transition state, it would be unreasonable to estimate bond lengths in the transition state from the experimental KER value.

\section{ACKNOWLEDGMENTS}

Work partly supported by the FWF, ÖAW, and ÖNB, Wien, Austria, and the European Commission, Brussels. Moreover, this work has been carried out within the Association EURATOM-ÖAW. Partial support from RFBR Project 01-03-02006 is gratefully acknowledged. The content of the publication is the sole responsibility of its publishers and it does not necessarily represent the views of the EU Commission or its services.

${ }^{1}$ D. Mathur, Phys. Rep. 225, 193 (1993).

${ }^{2} \mathrm{O}$. Echt and T. D. Märk, in Clusters of Atoms and Molecules II, edited by H. Haberland (Springer-Verlag, Berlin, 1994), Vol. 56, p. 183; D. Schröder and H. Schwarz, J. Phys. Chem. A 103, 7385 (1999); O. Echt, P. Scheier, and T. D. Märk, C. R. Physique 3, 353 (2002).

${ }^{3}$ H. Helm, K. Stephan, T. D. Märk, and D. L. Huestis, J. Chem. Phys. 74, 3844 (1981); D. Schröder, J. N. Harvey, and H. Schwarz, J. Phys. Chem. 102, 3639 (1998); R. Wesendrup, M. Pernpointner, and P. Schwerdtfeger, Phys. Rev. A 60, R3347 (1999).

${ }^{4}$ P. Tosi, R. Correale, W. L. Lu, S. Falcinelli, and D. Bassi, Phys. Rev. Lett. 82, 450 (1999).

${ }^{5}$ J. H. D. Eland and J. R. Sheahan, Chem. Phys. Lett. 223, 531 (1994).

${ }^{6}$ D. A. Hagan and J. H. D. Eland, Org. Mass Spectrom. 27, 855 (1992).

${ }^{7}$ M. Lundqvist, P. Baltzer, D. Edvardsson, L. Karlsson, and B. Wannberg, Phys. Rev. Lett. 75, 1058 (1995).

${ }^{8}$ B. Siegmann, U. Werner, H. O. Lutz, and R. Mann, J. Phys. B 34, L587 (2001).
${ }^{9}$ F. Scheuermann, E. Salzborn, F. Hagelberg, and P. Scheier, J. Chem. Phys. 114, 9875 (2001); T. A. Field and J. H. D. Eland, Int. J. Mass Spectrom. 192, 281 (1999).

${ }^{10}$ M. Rabrenovic, A. G. Brenton, and J. H. Beynon, Int. J. Mass Spectrom. Ion Processes 52, 175 (1983).

${ }^{11}$ T. Weiske, W. Koch, and H. Schwarz, J. Am. Chem. Soc. 115, 6312 (1993).

${ }^{12}$ K. Vekey and Z. Szilagyi, Int. J. Mass Spectrom. Ion Processes 165, 1 (1997).

${ }^{13}$ A. Vincze, J. Yinon, T. Peres, and C. Lifshitz, Int. J. Mass. Spectrom. 192, 99 (1999).

${ }^{14}$ P. Scheier, B. Dünser, and T. D. Märk, J. Phys. Chem. 99, 15428 (1995); C. Brechignac, P. Cahuzac, M. Defrutos, P. Garnier, and N. Kebaili, Phys. Rev. B 53, 1091 (1996); T. Schlathölter, R. Hoekstra, and R. Morgenstern, J. Phys. B 31, 1321 (1998).

${ }^{15}$ P. C. Hariharan and J. A. Pople, Chem. Phys. Lett. 16, 217 (1972).

${ }^{16}$ S. Matt, M. Sonderegger, R. David, O. Echt, P. Scheier, J. Laskin, C. Lifshitz, and T. D. Märk, Int. J. Mass. Spectrom. 187, 813 (1999).

${ }^{17}$ S. Matt-Leubner, A. Stamatovic, R. Parajuli, P. Scheier, T. D. Märk, O. Echt, and C. Lifshitz, Int. J. Mass Spectrom. 222, 213 (2003).

${ }^{18}$ R. G. Cooks, J. H. Beynon, R. M. Caprioli, and G. R. Lester, Metastable Ions (Elsevier, Amsterdam, 1973).

${ }^{19}$ M. Guilhaus, R. K. Boyd, A. G. Brenton, and J. H. Beynon, Int. J. Mass Spectrom. Ion Processes 67, 209 (1985).

${ }^{20}$ J. L. Holmes and A. D. Osborne, Int. J. Mass Spectrom. Ion Phys. 23, 189 (1977).

${ }^{21}$ M. F. Jarrold, J. Illies, N. J. Kirchner, W. Wagner-Redeker, M. T. Bowers, M. L. Mandich, and J. L. Beauchamp, J. Phys. Chem. 87, 2213 (1983).

${ }^{22}$ R. Parajuli, P. Scheier, V. Grill, S. Matt, O. Echt, and T. D. Märk, Chem. Phys. Lett. 330, 53 (2000).

${ }^{23}$ M. J. Frisch, G. W. Trucks, H. B. Schlegel et al. Gaussian 98 (Gaussian, Inc., Pittsburgh, PA, 1998).

${ }^{24}$ R. A. Kendall, J. T. H. Dunning, and R. J. Harrison, J. Chem. Phys. 96, 6796 (1992).

${ }^{25}$ J. Baker, Chem. Phys. Lett. 159, 447 (1989).

${ }^{26}$ T. P. Hamilton and H. F. Schaefer, J. Phys. Chem. 93, 7560 (1989).

${ }^{27}$ B. S. Jursic, Int. J. Quantum Chem. 72, 571 (1999).

${ }^{28}$ S. Hayakawa, M. Takahashi, K. Arakawa, and M. Morishita, J. Chem. Phys. 110, 2745 (1999). 